\title{
Beta-adrenergic receptors in the lateral nucleus of the amygdala contribute to the acquisition but not the consolidation of auditory fear conditioning
}

\author{
David E. A. Bush', Ellen M. Caparosa' , Anna Gekker' and Joseph LeDoux ${ }^{1,3 *}$ \\ W. M. Keck Foundation Laboratory of Neurobiology, Center for Neural Science, New York University, New York, NY, USA \\ 2 Department of Clinical and Social Sciences in Psychology, University of Rochester, Rochester, MN, USA \\ ${ }^{3}$ Emotional Brain Institute Labs, Nathan Kline Institute, Orangeburg, New York, NY, USA
}

Edited by:

Regina M. Sullivan, University of Oklahoma, USA

Reviewed by:

Jeansok J. Kim, University of

Washington, USA

Devin Mueller, University of Wisconsin, USA

\section{*Correspondence:}

Joseph LeDoux, W. M. Keck

Foundation Laboratory of

Neurobiology, Center for Neural

Science, New York University, NY, USA.

e-mail: ledoux@cns.nyu.edu
Beta-adrenergic receptors ( $\beta A R s$ ) have long been associated with fear disorders and with learning and memory. However, the contribution of these receptors to Pavlovian fear conditioning, a leading behavioral model for studying fear learning and memory, is still poorly understood. The aim of this study was to investigate the involvement of $\beta A R$ activation in the acquisition, consolidation and expression of fear conditioning. We focused on manipulations of $\beta$ ARs in the lateral nucleus of the amygdala (LA) because of the well-established contribution of this area to fear conditioning. Specifically, we tested the effects of intra-LA microinfusions of the $\beta A R$ antagonist, propranolol, on learning and memory for auditory Pavlovian fear conditioning in rats. Pre-training propranolol infusions disrupted the initial acquisition, short-term memory (STM), and long-term memory (LTM) for fear conditioning, but infusions immediately after training had no effect. Further, infusion of propranolol prior to testing fear responses did not affect fear memory expression. These findings indicate that amygdala $\beta A R s$ are important for the acquisition but not the consolidation of fear conditioning.

Keywords: acquisition, beta-adrenergic, consolidation, fear conditioning, lateral amygdala, norepinephrine

\section{INTRODUCTION}

Norepinephrine (NE) has long been implicated in fear and anxiety (Gray, 1978; Aston-Jones and Bloom, 1981; Aston-Jones et al., 1999, 2000; Sullivan et al., 1999; McGaugh et al., 2002), and is known to play a role in learning, memory and plasticity (Bailey et al., 2000; McGaugh et al., 2002; Roozendaal et al., 2004; Tully et al., 2007). Nevertheless, the contribution of NE to Pavlovian fear conditioning, a leading model for understanding the neural basis of fear and anxiety and learning and memory, is not well understood.

There have been many studies of NE contributions to aversive memory tasks, especially inhibitory avoidance (IA) (McGaugh, 2004; Roozendaal et al., 2008). These studies clearly show that NE, acting via beta-adrenergic receptors ( $\beta$ ARs), contributes to the consolidation of long-term memory (LTM) of IA. This has been shown in studies in which NE or $\beta A R$ agonists or antagonists are given immediately after training, either systemically or within the lateral (LA) and basal (B) amygdala. In contrast, studies of auditory fear conditioning have failed to find effects of immediate post-training treatment with NE or the $\beta A R$ antagonist propranolol given systemically (Lee et al., 2001), and post-training infusions of propranolol into in the LA and B also fail to have an effect on LTM (Debiec and LeDoux, 2004). This discrepancy between results in IA and fear conditioning tasks is not restricted to NE manipulations (e.g. Bueno et al., 1993; Wilensky et al., 2000). Most likely, the differences between the paradigms are due to the fact that in auditory fear conditioning memory is consolidated in the amygdala (Schafe et al., 1999; Schafe and LeDoux, 2000; Rodrigues et al., 2004), whereas IA memory formation is hippocampal dependent (O’Keefe and Nadel, 1978) with the amygdala modulating hippocampal learning and storage (McGaugh, 2000). It is thus not possible to use findings from IA tasks to explain the role of NE in the formation of memory for amygdala-dependent fear conditioning.

In the present study, we therefore sought to systematically explore the contribution of $\beta$ ARs to auditory fear conditioning in the LA. We first replicated, using a range of doses, the finding that infusion of propranolol into the LA fails to affect fear memory consolidation. Next, we examined the effects of pre-training infusions of the same range of propranolol doses, and found that LTM was impaired. If the LTM impairment produced by pre-training infusions was due to an effect on learning, pre-training infusion of propranolol should also impair short-term memory (STM). Indeed, this was found. Finally, we examined effects of pre-testing infusion of propranolol in the LA on fear expression to rule out the possibility that a deficit in expression during training accounts for the effects on learning. Together, the results suggest that $\beta$ ARs in the LA are involved in the acquisition, but not the consolidation or expression, of memory for auditory fear conditioning.

\section{MATERIALS AND METHODS ANIMALS}

Adult male Sprague-Dawley rats were obtained from Hilltop Laboratory Animals, Inc. (Scottdale, PA, USA) at a weight of 275$300 \mathrm{~g}$ upon arrival. Rats were individually housed in transparent plastic Nalgene cages and maintained on a 12/12 h light/dark cycle (lights on at 7:00 AM) within a temperature- and humidity-controlled environment. Food and water were available ad libitum throughout 
the duration of the experiments. All procedures were conducted in accordance with the National Institutes of Health Guide for the Care and Use of Experimental Animals and were approved by the New York University Animal Care and Use Committee.

\section{STEREOTAXIC SURGERY}

Rats were anesthetized with a mixture of ketamine (Ketaject ${ }^{\circledR}$; $100 \mathrm{mg} / \mathrm{kg}$, i.p.) and xylazine (Xyla-Ject ${ }^{\circledR} ; 10 \mathrm{mg} / \mathrm{kg}$, i.p.), with supplementation as needed, along with buprenorphine- $\mathrm{HCl}$ (Buprenex ${ }^{\circledR} 0.02 \mathrm{mg} / \mathrm{kg}$, s.c.) for analgesia, and placed in a stereotaxic apparatus (David Kopf Instruments, Tujunga, CA, USA). Supplemental doses of the mix were given as needed to maintain a deep level of anesthesia. Body temperature was maintained with a heated gel pad. Stainless steel guide cannulae (22 gauge; Plastics One, Roanoke, VA, USA), fitted with 28 gauge internal cannulae that extended $1.5 \mathrm{~mm}$ beyond the guides, were lowered into the LA using the following coordinates from Paxinos and Watson (1998) (28) for the LA: $-3.2 \mathrm{~mm}$ anteroposterior (AP), $\pm 5.5 \mathrm{~mm}$ mediolateral (ML), and $-8.0 \mathrm{~mm}$ dorsoventral (DV) from the skull. The cannulae were secured to the skull using surgical screws and acrylic dental cement. Twenty-eight gauge dummy cannulae, cut to extend $0.5 \mathrm{~mm}$ from the guides, were inserted to prevent clogging (29-32). After surgery, rats were administered buprenorphine hydrochloride (Buprenex ${ }^{\circledR} 0.02 \mathrm{mg} / \mathrm{kg}$, s.c.) for analgesia, and given at least 7 days to recover from surgery prior to behavioral manipulations.

\section{DRUG PREPARATION AND MICROINFUSIONS}

Propranolol ( $( \pm)$-Propranolol hydrochloride) was obtained from Sigma-Aldrich Co. (St. Louis, MO, USA), and freshly dissolved in artificial cerebrospinal fluid (ACSF) immediately prior to injections. Concentrations were prepared for three dose groups: $0,0.1$, or $1.0 \mu \mathrm{g} / 0.25 \mu \mathrm{l} / \mathrm{side}$. For the drug infusions, internal infusion cannulae were attached to $1.0 \mu$ l Hamilton syringes via .015 " $\times .043$ " $\times .014$ " polyethylene tubing obtained from A-M Systems, Inc. (Carlsborg, WA, USA). Each tubing and syringe was backfilled with distilled water, and a small air bubble separated the water from the infusate. While held in the experimenter's lap, rats were bilaterally infused with $0.25 \mu \mathrm{l}$ using an infusion pump that delivered drug at a constant rate of $0.15 \mu \mathrm{l} / \mathrm{min}$. Cannulae were left in place for an additional $75 \mathrm{~s}$ to allow drug diffusion away from the cannula tip.

\section{FEAR CONDITIONING APPARATUS AND STIMULI}

Rats underwent habituation and fear conditioning in one of four identical chambers constructed of aluminum and Plexiglas walls (Rat Test Cage, Coulbourn Instruments, Allentown, PA, USA), with metal stainless steel rod flooring that was attached to a shock generator (Model H13-15; Coulbourn Instruments). The chambers were lit with a single house light, and each chamber was enclosed within a sound-isolation cubicle (Model H10-24A; Coulbourn Instruments). Fear testing took place within a modified version of the context, with smooth black plastic flooring, mild peppermint scent, and dim red lighting. An infrared digital camera, mounted on top of each chamber, allowed videotaping during behavioral procedures for subsequent behavioral scoring. A computer, installed with Graphic State 2 software and connected to the chambers via the Habitest Linc System (Coulbourn Instruments), controlled the presentation of stimuli during behavioral sessions. Chamber rod and plastic floors, trays and walls were thoroughly cleaned with water and dried between sessions. All rats were given handling and a 30-min habituation session to the fear conditioning context on a day prior to fear conditioning, and also given a 5-min acclimation period to freely explore the chamber before onset of the first stimulus during training and testing sessions.

\section{FEAR CONDITIONING AND TESTING PROCEDURES}

Conditioning was conducted in groups of four rats at a time, each in a different chamber. Following the initial 5-min acclimation period, all rats were presented with three conditioning trials (CS-US pairings) on Day 1 . The CS was a $30-\mathrm{s}, 5 \mathrm{kHz}, 80 \mathrm{~dB}$ SPL sine wave tone, which co-terminated with a 1-s, $0.6 \mathrm{~mA}$ footshock US. The mean inter-trial interval was $4 \mathrm{~min}$ (2-6 min range) for both conditioning and testing sessions. After conditioning, rats were returned to their home cages within the colony room.

Testing for CS-elicited fear was conducted in the modified context on Day 3, 2 days after conditioning. After the 5-min acclimation period, rats were presented with three CS-alone presentations, using the same stimulus parameters as in conditioning, but excluding the footshock US. Behavior was recorded and freezing was scored as described below.

\section{MEASUREMENT OF FREEZING BEHAVIOR}

Freezing was used to measure the conditional fear response, and was defined as the cessation of all movement with the exception of respiration-related movement and non-awake or rest body posture (McAllister and McAllister, 1971; Fanselow, 1994). Behavior was videotaped and later scored offline with a digital stopwatch by recording the total time spent freezing during every 30-s tone CS. Pre-CS freezing was also scored during the 30 -s interval prior to the initial tone onset, and was used as a measure of non-specific freezing to the context. Freezing was scored by an experimenter blind to drug group allocation.

\section{HISTOLOGY}

To verify the intra-amygdala placement of the injection cannula tips, following behavioral procedures rats were anesthetized with an overdose of chloral hydrate $(25 \%, 1 \mathrm{ml} / 100 \mathrm{~g})$ and transcardially perfused with $10 \%$ buffered formalin. Brains were removed and stored in a solution containing 30\% sucrose dissolved in 10\% buffered formalin. Subsequently, brains were blocked, and cut in $50-\mu \mathrm{m}$ sections through the amygdala using a freezing microtome. After standard histological Nissl-staining, sections were examined on a light microscope for injector tip localization into the amygdala. Only data from rats that had bilateral injector placements localized to the LA were included in the study. Of 127 rats that received cannula implants, 47 were removed following histological examination because of misplaced cannulae. Samples sizes indicated for each experiment below refer to rats with injection sites successfully localized to the LA.

\section{STATISTICAL ANALYSIS}

Mean behavioral freezing scores from the three-trial testing sessions were evaluated using analysis of variance (ANOVA), to test for the effect of propranolol dose. Rats were also evaluated for freezing during the pre-CS 30-s interval just prior to the first CS presentation during the testing session to evaluate freezing not specific to the tone CS. Nine rats that showed greater than $50 \%$ freezing during the pre-CS period 
were eliminated. Lastly, to evaluate propranolol effects on immediate (within-session) acquisition behavior, an ANOVA on propranolol dose was conducted across training session data from all experiments to compare learning between rats given different propranolol treatments, using mean freezing scores during the second and third CS trials (the first CS trial that preceded the first US was excluded). For all tests, significant ANOVA results were followed up using Fisher's LSD post hoc test for comparisons among three means. Statistica 8 (StatSoft, Inc., Tulsa, OK, USA) was used for the analyses. All data are presented as mean \pm standard error of the mean (SEM).

\section{EXPERIMENT 1: EFFECTS OF POST-TRAINING INTRA-LA PROPRANOLOL ON LTM FOR FEAR CONDITIONING}

To assess the effects of immediate post-training infusions of propranolol in LA on LTM for auditory fear conditioning, 15 rats were administered bilateral microinjections of one of three doses of propranolol $(0,0.1$, or $1.0 \mu \mathrm{g}$ in $0.25 \mu \mathrm{l}$ ACSF $)$ immediately after fear conditioning. Two days later the rats were tested drug-free for CS-elicited freezing in the modified context.

\section{EXPERIMENT 2: EFFECTS OF PRE-TRAINING INTRA-LA PROPRANOLOL ON LTM FOR FEAR CONDITIONING}

To assess the effects of pre-training infusion of propranolol in LA on LTM for fear conditioning, 19 rats were administered bilateral microinjections of one of three doses of propranolol $(0,0.1$, or $1.0 \mu \mathrm{g}$ in $0.25 \mu \mathrm{l} \mathrm{ACSF}$ ) approximately $30 \mathrm{~min}$ prior to fear conditioning. Two days later rats were tested drug-free for CS-elicited freezing in the modified context.

\section{EXPERIMENT 3: EFFECTS OF PRE-TRAINING INTRA-LA PROPRANOLOL ON STM FOR FEAR CONDITIONING}

To assess the effects of propranolol on STM for fear conditioning, 19 rats were administered pre-training propranolol microinjections as in Experiment 2, except that the test for CS-elicited freezing in the modified context was given three hours after conditioning. A second test for LTM was also given 2 days later.

\section{EXPERIMENT 4: EFFECTS OF PRE-TESTING INTRA-LA PROPRANOLOL ON FEAR MEMORY EXPRESSION}

To test whether or not intra-amygdala infusion of propranolol interferes with the expression of a previously formed fear memory, 18 rats were given fear conditioning drug-free, and then 2 days later given one of three doses of propranolol $(0,0.1$, or $1.0 \mu \mathrm{g}$ in $0.25 \mu \mathrm{ACSF}$ ) approximately $30 \mathrm{~min}$ prior to testing for CS-elicited freezing in the modified context.

\section{RESULTS}

We assessed whether or not intra-LA administration of the beta-AR antagonist, propranolol, would affect the acquisition, consolidation, or expression of memory for auditory fear conditioning. For all experiments only rats with confirmed placements in the LA were included in the analysis (Figure 1).

\section{EXPERIMENT 1: POST-TRAINING PROPRANOLOL DOES NOT AFFECT LTM FOR FEAR CONDITIONING}

Numerous studies have found that immediate post-training manipulations of $\beta$ ARs disrupt the consolidation of IA learning, whereas several studies have failed to find an effect on fear conditioning (see "Introduction"). We therefore attempted to replicate with our paradigm the lack of an effect of post-training manipulations of $\beta$ ARs with propranolol. Most previous studies of fear conditioning have used systemic manipulations. The only previous study to use intra-LA infusions used only a single dose (Debiec and LeDoux, 2004). We used three doses of propranolol infused into LA in different groups. Results from the LTM test showed that post-training propranolol did not affect freezing during the test $\left(F_{2,12}=0.29\right.$; $p=0.75$ ), regardless of the dose (Figure 2).

\section{EXPERIMENT 2: PRE-TRAINING LA PROPRANOLOL IMPAIRS LTM FOR FEAR CONDITIONING}

In this experiment we tested whether pre-training infusions of propranolol into LA, in contrast to post-training infusions, might disrupt fear conditioning. Results from the LTM test in rats given

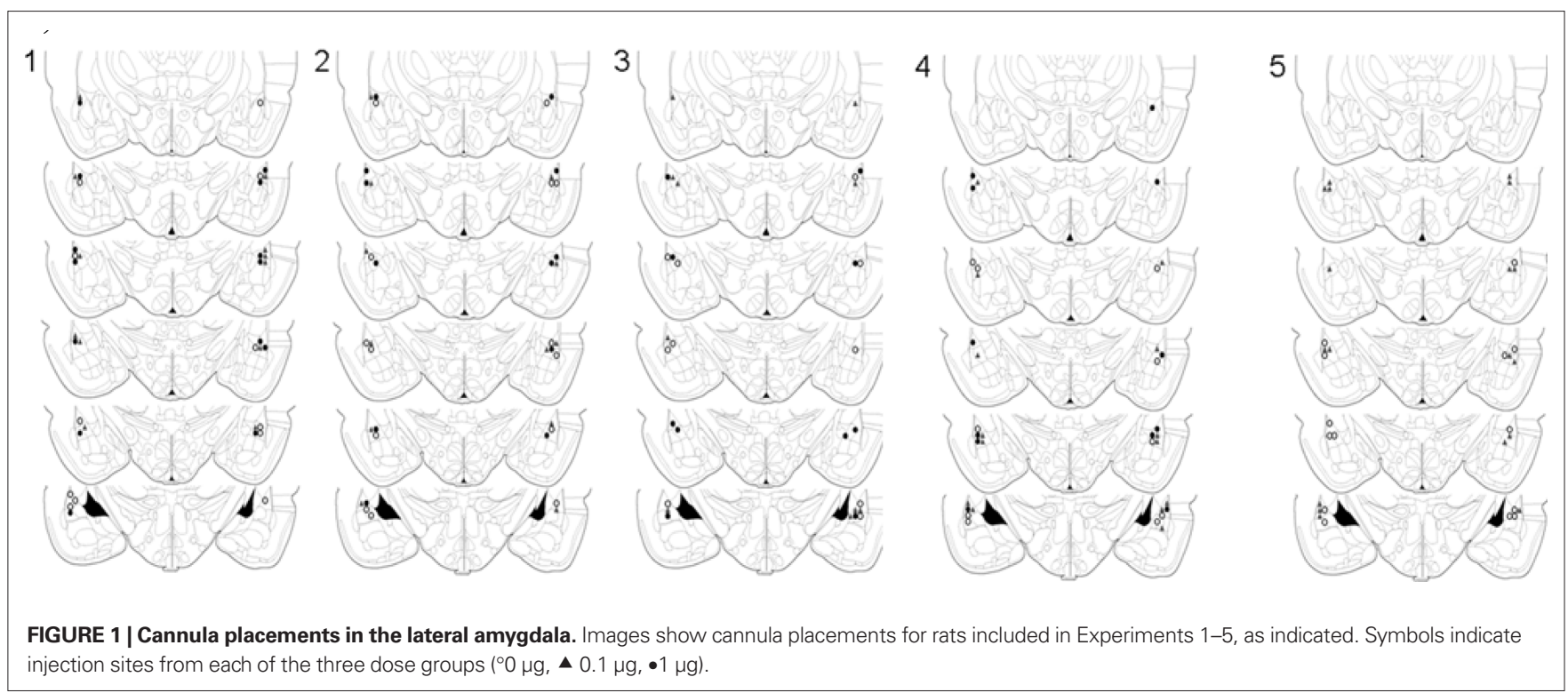


pre-training propranolol showed a significant main effect of propranolol dose $\left(F_{2,16}=9.08 ; p<0.01\right)$, and mean comparisons indicated that 0.1 and $1.0 \mu \mathrm{g}$ propranolol dose groups had significantly lower levels of freezing compared with the vehicle control group $(p<0.01)$. Thus, pre-training propranolol microinjections into the LA significantly attenuated LTM for auditory fear conditioning (Figure 3).

\section{EXPERIMENT 3: PRE-TRAINING PROPRANOLOL IMPAIRS BOTH STM AND LTM FOR FEAR CONDITIONING}

Pre-training infusions in LA could have effects on LTM because they disrupt learning or because they disrupt post-training consolidation (conversion of intact STM into LTM). A deficit in STM and LTM after pre-training infusion of propranolol in LA would thus be consistent with a disruption of acquisition while intact STM but impaired LTM after pre-training infusion of propranolol in LA would be consistent with disruption of consolidation. Results from the STM test in rats given pre-training propranolol showed a significant main effect of propranolol dose on STM $\left(F_{2,16}=7.44\right.$; $p<0.01)$. Mean comparisons indicated that both the 0.1 or $1.0 \mu \mathrm{g}$ propranolol groups had significantly lower levels of freezing compared with the vehicle control group $(p<0.01)$. The LTM test for the same rats showed that the disruption of STM was still evident 2 days later $\left(F_{2,16}=9.37 ; p<0.01\right)$, with both 0.1 and $1.0 \mu \mathrm{g}$ propranolol groups at significantly lower levels than the vehicle control group $(p<0.01)$, confirming the results from Experiment 1. Thus, pre-training propranolol microinjections into the LA significantly attenuated both STM and LTM for auditory fear conditioning (Figure 4).

The effects on STM could be due to a failure to acquire fear conditioning, or instead to a disruption of the maintenance of STM once acquired. In an attempt to distinguish these possibilities, effects of infusions of propranolol into the LA were assessed

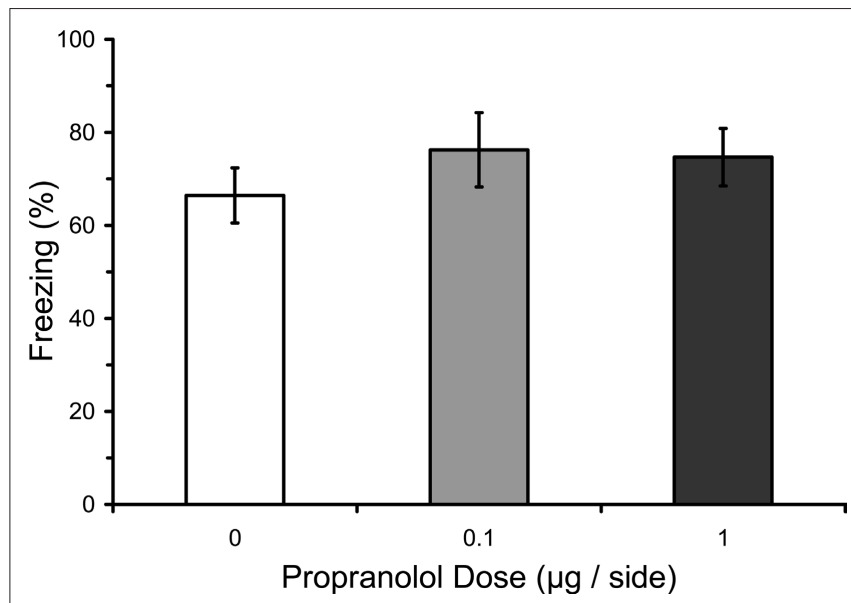

FIGURE 2 | Post-training propranolol does not affect LTM for fear conditioning. Rats from Experiment 3 were given microinfusions of propranolol $(0 \mu \mathrm{g}, n=5 ; 0.1 \mu \mathrm{g}, n=5 ; 1 \mu \mathrm{g}, n=5)$ into the lateral amygdala (LA) immediately after three-trial auditory fear conditioning. Post-training propranolol had no effect on long-term memory (LTM) for fear conditioning when tested drug-free 2 days later. The figure depicts mean freezing levels during the LTM test. on the acquisition of CS-US during the fear conditioning session. Mean freezing levels during the second and third CS presentations of training were analyzed in rats given pre-training propranolol doses in Experiments 1-2. Results showed a significant effect of pre-training manipulation on freezing during the training session $\left(F_{2,35}=5.02 ; p=0.01\right)$. Mean comparisons indicated that rats pretreated with both 0.1 or $1.0 \mu \mathrm{g}$ propranolol groups before training had significantly lower levels of freezing during the training session, compared with rats that were pre-treated with vehicle

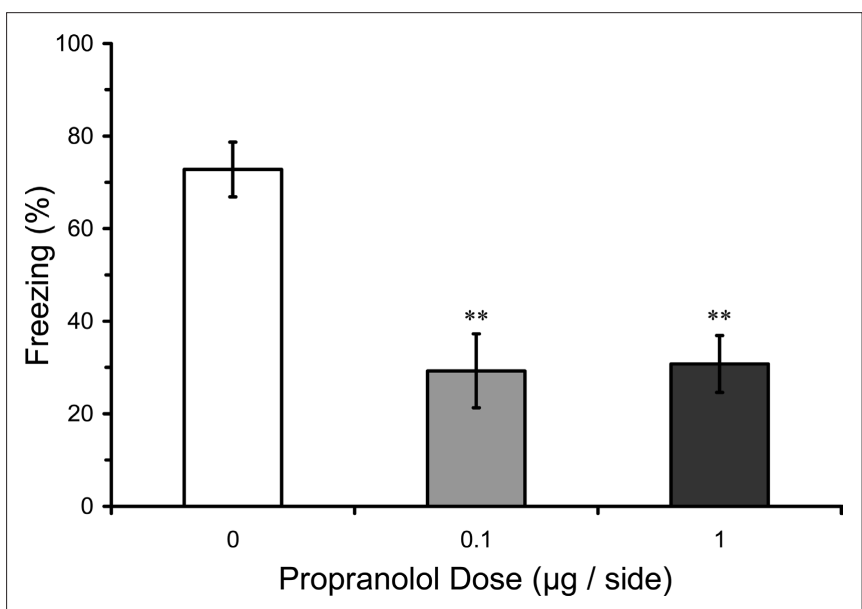

FIGURE 3 | Pre-training propranolol disrupts LTM for fear conditioning. Rats from Experiment 1 were given microinfusions of propranolol $(0 \mu \mathrm{g}, n=6$; $0.1 \mu \mathrm{g}, n=6 ; 1 \mu \mathrm{g}, n=7$ ) into the lateral amygdala (LA) prior to three-trial auditory fear conditioning. Propranolol pre-treated rats showed attenuated long-term memory (LTM) for fear conditioning when tested drug-free 2 days later. The figure depicts mean freezing levels during the LTM test. ** indicates significantly lower freezing relative to vehicle $(p<0.01)$.

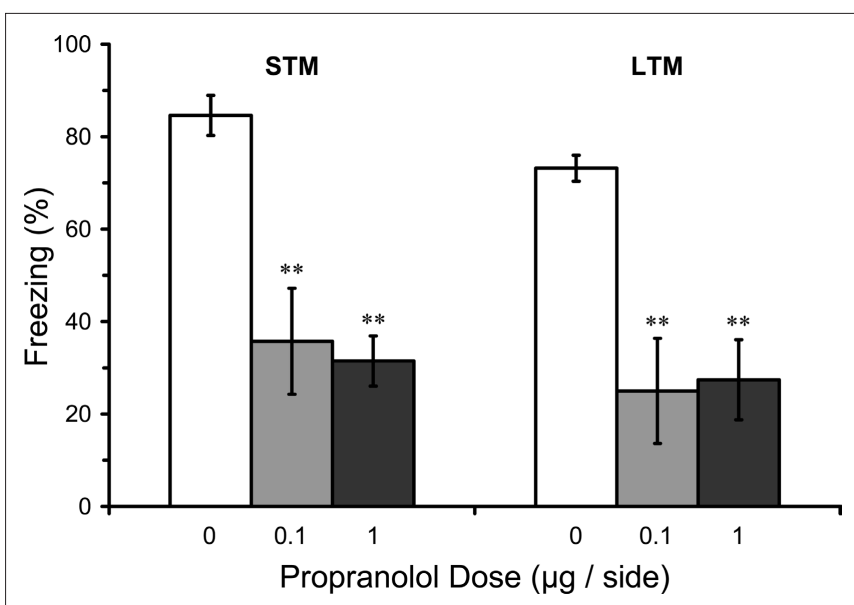

FIGURE 4 | Pre-training propranolol disrupts STM and LTM for fear conditioning. Rats from Experiment 2 were given microinfusions of propranolol $(0 \mu \mathrm{g}, n=7 ; 0.1 \mu \mathrm{g}, n=6 ; 1 \mu \mathrm{g}, n=6)$ into the lateral amygdala (LA) prior to three-trial auditory fear conditioning. Propranolol pre-treated rats showed attenuated short-term memory (STM) when tested at three hours after fear conditioning, and memory was still impaired when tested for long-term memory (LTM) 2 days later. The figure depicts mean freezing levels during the STM and LTM tests. ** indicates significantly lower freezing relative to vehicle $(p<0.01)$. 
( $p=0.01$ ). These results suggest that LA propranolol attenuates learning of the CS-US association during the fear conditioning session (Figure 5).

The findings in Experiment 3 are thus consistent with the conclusions from Experiments 1 and 2. They suggest that $\beta$ ARs in the LA are involved in the acquisition but not consolidation of fear memory.

\section{EXPERIMENT 4: PRE-TESTING PROPRANOLOL DOES NOT AFFECT FEAR MEMORY EXPRESSION}

One possible explanation for the effects of pre-training propranolol on fear conditioning is that intra-amygdala propranolol has immediate effects on fear expression that results in an indirect attenuation of fear expression during the conditioning procedure. Indeed, $\beta A R$ antagonists such as propranolol are sometimes used to treat stage fright and other fear symptoms (James et al., 1978; Brantigan et al., 1979; Neftel et al., 1982; Lehrer et al., 1987). To test whether or not intra-amygdala propranolol disrupts fear expression, rats were microinfused with propranolol before testing fear triggered by an established fear CS. Results showed no effect of pre-testing propranolol on freezing during the test $\left(F_{2,15}=0.01 ; p=0.99\right)$, indicating that propranolol does not affect the expression of conditioned fear (Figure 6), at least not when delivered directly into the amygdala. Effects reported in humans may be due to actions in other brain areas or in the peripheral nervous system (Conant et al., 1989).

\section{DISCUSSION}

The present study examined the effects of intra-amygdala blockade of $\beta$ ARs using the $\beta$ AR antagonist propranolol on Pavlovian fear conditioning. The main finding was that propranolol disrupted LTM when given before, but not immediately after, the training session. The success of pre-training infusions in disrupting freezing

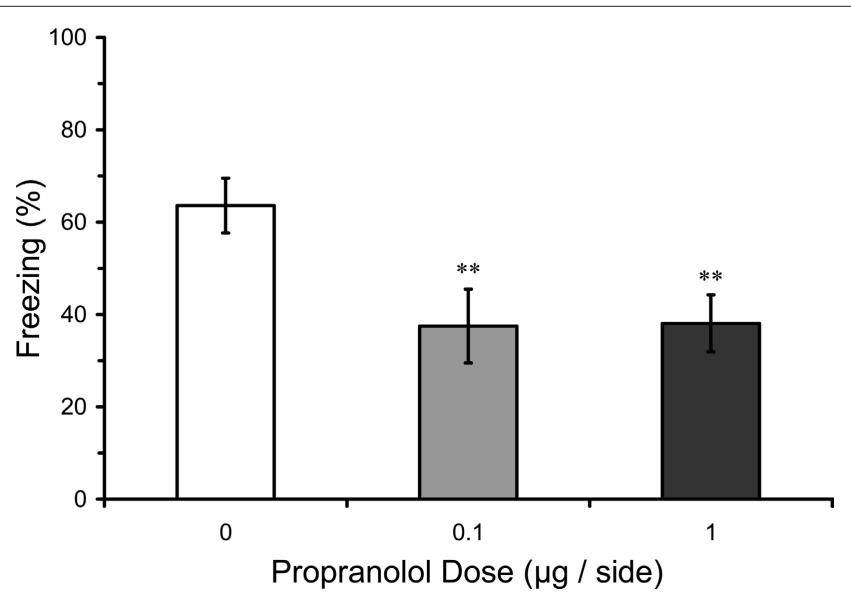

FIGURE 5 | Pre-training propranolol disrupts within-session fear acquisition. Propranolol pre-treated rats from Experiments 1 and $2(0 \mu \mathrm{g}$, $n=13 ; 0.1 \mu \mathrm{g}, n=12 ; 1 \mu \mathrm{g}, n=13$ ) showed impaired freezing to the auditory conditioned stimulus (CS) within the fear conditioning session. The figure depicts mean freezing levels during the second and third trials of the three-trial training session. ${ }^{*}$ indicates significantly lower freezing relative to vehicle $(p=0.01)$. during training, during a STM test, and during a LTM test, and the failure of immediate post-training infusions or pre-testing infusions to affect LTM, strongly argues that $\beta$ ARs in the LA contribute to the acquisition but not the consolidation of the memory of the auditory fear conditioning experience.

Previous studies of fear conditioning have consistently failed to find effects of noradrenergic transmission on the consolidation of fear conditioning using systemic drug injections (Lee et al., 2001; Debiec and LeDoux, 2004; Grillon et al., 2004) or genetic manipulation (Murchison et al., 2004). Only one study examined the effects of intra-LA propranolol on fear conditioning (Debiec and LeDoux, 2004). This study also failed to find an effect, but only one dose was tested. In the present study we confirmed with a range of doses that intra-LA infusion of propranolol fails to disrupt consolidation.

Studies using other behavioral paradigms have found effects of systemic (Przybyslawski et al., 1999) and intra-amygdala (Hatfield and McGaugh, 1999) infusions of propranolol on the consolidation of aversive conditioning using an IA paradigm (McGaugh, 2000). Effects have also been found on spatial learning (Fanelli et al., 1985). These tasks, in contrast to auditory fear conditioning, depend on the hippocampus. It is thus possible that $\beta$ ARs contribute to consolidation of hippocampal but not amygdala memory storage. This is consistent with other findings showing that $\beta$ ARs are involved in the consolidation of contextual fear conditioning, which is hippocampal dependent (Kim and Fanselow, 1992; Phillips and LeDoux, 1994).

What, then, might be the basis for the effects on the acquisition of fear conditioning? Studies using an in vitro slice preparations show that stimulation of $\beta$ ARs can induce synaptic plasticity in the hippocampus and amygdala, and that blockade of these receptors dampens long-term synaptic plasticity induced by stimulation of afferent inputs (Huang et al., 2000; Johnson et al., 2006; Tully et al., 2007; Johnson et al., in preparation). It is thus possible that intra-LA blockade of $\beta$ ARs disrupts the synaptic plasticity that underlies fear acquisition.

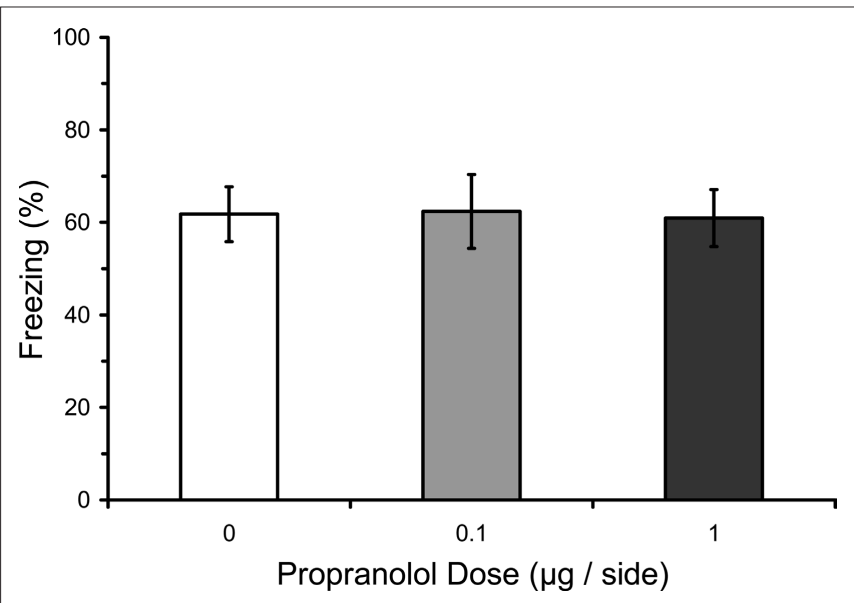

FIGURE 6 | Pre-testing propranolol does not affect fear expression. Rats from Experiment 4 were fear conditioned, and then 2 days later given microinfusions of propranolol $(0 \mu \mathrm{g}, n=5 ; 0.1 \mu \mathrm{g}, n=7 ; 1 \mu \mathrm{g}, n=6)$ into the lateral amygdala (LA) immediately before a fear memory test. Propranolol had no effect on fear memory expression. The figure depicts mean freezing levels during the expression test. 
During alert, non-stressed states the locus coeruleus exhibits low tonic and high phasic firing, while threatening or stressful conditions elicit high tonic firing rates (Aston-Jones and Bloom, 1981; Grant and Redmond, 1984; Grant et al., 1988; Aston-Jones et al., 1999, 2000; McIntyre et al., 2002) and high levels of NE release (McIntyre et al., 2002). NE and $\beta$ ARs could contribute to learning by way of the basal or background level of $\beta A R$ activation (Mana and Grace, 1997) or by way of stimulation induced increases in activation (Galvez et al., 1996).

One possible hypothesis about the cellular role of NE in fear plasticity is that it simply facilitates glutamatergic, NMDAdependent, Hebbian plasticity. However, cellular studies in the rodent hippocampus (Winder et al., 1999) and LA (Huang et al., 2000; Johnson et al., 2006; Tully et al., 2007; Johnson et al., in preparation) suggest that activation of $\beta$ ARs is itself sufficient to induce long-term plasticity. NE may therefore play a significant role in enabling learning.

An alternative possible explanation of the effects of $\beta A R$ blockade in the LA on the acquisition of fear conditioning could be that the drug had a non-specific inactivating effect on amygdala processing, similar to functional inactivation (Muller et al., 1997; Wilensky et al., 1999; Wilensky et al., 2000). However, given that there was no effect of propranolol when administered before the test of fear expression, which also depends on the LA, it appears that propranolol does not inactivate or disrupt the LA. One more explanation might be that propranolol attenuated footshock sensitivity, but in contrast to causing antinociception, propranolol has previously been shown to inhibit antinociception

\section{REFERENCES}

Aston-Jones, G., and Bloom, F. E. (1981). Norepinephrine-containing locus coeruleus neurons in behaving rats exhibit pronounced responses to non-noxious environmental stimuli. J. Neurosci. 1, 887-900.

Aston-Jones, G., Rajkowski, J., and Cohen, J. (1999). Role of locus coeruleus in attention and behavioral flexibility. Biol. Psychiatry 46, 1309-1320.

Aston-Jones, G., Rajkowski, J., and Cohen, J. (2000). Locus coeruleus and regulation of behavioral flexibility and attention. Prog. Brain Res. 126, 165-182.

Bailey, C. H., Giustetto, M., Huang, Y. Y., Hawkins, R. D., and Kandel, E. R. (2000). Is heterosynaptic modulation essential for stabilizing Hebbian plasticity and memory? Nat. Rev. Neurosci. 1, 11-20.

Brantigan, C. O., Brantigan, T. A., and Joseph, N. (1979). The effect of beta blockade on stage fright. A controlled study. Rocky Mt. Med. J. 76, 227-233.

Bueno, O. F., Oliveira, M. G., Pomarico, A. C., and Gugliano, E. B. (1993). A dissociation between the proactive ECS effects on inhibitory avoidance learning and on classical fear conditioning. Behav. Neural Biol. 59, 180-185.

Conant, J., Engler, R., Janowsky, D., Maisel, A., Gilpin, E., and LeWinter, M. (1989).

in the tail-flick test produced by systemic baclofen (Sabetkasai et al., 1997) or amygdala stimulation (Oliveira and Prado, 1998), and propranolol treatments that impair inhibitory avoidance retention are reported to have no effect on footshock sensitivity (Nielson et al., 1999). These findings suggest that the current effect on freezing during fear conditioning was not caused by reduced shock sensitivity.

The lack of effect of intra-amygdala propranolol on fear expression is somewhat surprising in light of the use of beta-blockers to relieve symptoms associated with stage fright and related aspects of fear arousal in humans (James et al., 1978; Brantigan et al., 1979; Neftel et al., 1982; Lehrer et al., 1987). One possible explanation for these findings is that the fear reducing effects due to the reduction of peripheral ANS arousal and its stimulating affects on the CNS rather than to a direct action in the CNS. However, recent studies in rats found that propranolol, which crosses the blood brain barrier, reduced conditioned fear, but sotalol, which acts only peripherally, did not (Rodriguez-Romaguera et al., 2009). This suggests that propranolol may act in areas other than LA to reduce fear expression. Two possible candidates are the central nucleus of the amygdala, which directly controls fear expression (LeDoux, 2000), or the medial prefrontal cortex, which modulates fear expression (Sotres-Bayon et al., 2004; Quirk et al., 2006).

In summary, the results of this study implicate amygdala $\beta A R$ activation as important for the acquisition, but not the consolidation, of Pavlovian fear conditioning. Further studies will be required to tease apart the exact contribution of $\beta$ ARs to synaptic plasticity underlying these effects on learning.

Gray, J.A. (1978). The neuropsychology of anxiety. Br. J. Psychol. 69, 417-434.

Grillon, C., Cordova, J., Morgan, C. A., Charney, D. S., and Davis, M. (2004). Effects of the beta-blocker propranolol on cued and contextual fear conditioning in humans. Psychopharmacology (Berl.) 175, 342-352.

Hatfield, T., and McGaugh, J. L. (1999). Norepinephrine infused into the basolateral amygdala posttraining enhances retention in a spatial water maze task. Neurobiol. Learn. Mem. 71, 232-239.

Huang, Y. Y., Martin, K. C., and Kandel, E. R. (2000). Both protein kinase A and mitogen-activated protein kinase are required in the amygdala for the macromolecular synthesis-dependent late phase of long-term potentiation. J. Neurosci. 20, 6317-6325.

James, I. M., Pearson, R. M., Griffith, D. N., Newbury, P., and Taylor, S. H. (1978). Reducing the somatic manifestations of anxiety by beta-blockade--a study of stage fright. J. Psychosom. Res. 22, 327-337.

Johnson, L. R., Hou, M., and LeDoux, J. E. (2006). Afferent specific regulation of cortical and subcortical synaptic input to the lateral amygdala by norepinephrine. Soc. Neurosci. Abstr. 370.10
Kim, J. J., and Fanselow, M. S. (1992). Modality-specific retrograde amnesia of fear. Science 256, 675-677.

LeDoux, J. E. (2000). Emotion circuits in the brain. Annu. Rev. Neurosci. 23, 155-184.

Lee, H. J., Berger, S. Y., Stiedl, O., Spiess, J., and Kim, J. J. (2001). Post-training injections of catecholaminergic drugs do not modulate fear conditioning in rats and mice. Neurosci. Lett. 303, 123-126.

Lehrer, P. M., Rosen, R. C., Kostis, J. B., and Greenfield, D. (1987). Treating stage fright in musicians: the use of beta blockers. N.J. Med. 84, 27-33.

Mana, M. J., and Grace, A. A. (1997). Chronic cold stress alters the basal and evoked electrophysiological activity of rat locus coeruleus neurons. Neuroscience 81, 1055-1064.

McAllister, W. R., and McAllister, D. E. (1971). "Behavioral measurement of conditioned fear," in Aversive Conditioning and Learning, ed. F.R. Brush (New York: Academic Press), 105-179.

McGaugh, J. L. (2000). Memory - a century of consolidation. Science 287, 248-251.

McIntyre, C. K., Hatfield, T., and McGaugh, J. L. (2002). Amygdala norepinephrine levels after training 
predict inhibitory avoidance retention performance in rats. Eur. J. Neurosci. 16, 1223-1226.

McGaugh, J. L. (2004). The amygdala modulates the consolidation of memories of emotional arousing experiences. Annu. Rev. Neurosci. 27, 1-28

McGaugh, J.L., McIntyre, C.K., and Power, A.E. (2002). Amygdala modulation of memory consolidation: interaction with other brain systems. Neurobiol. Learn Mem. 78, 539-552.

Muller, J., Corodimas, K. P., Fridel, Z., and LeDoux, J. E. (1997). Functional inactivation of the lateral and basal nuclei of the amygdala by muscimol infusion prevents fear conditioning to an explicit conditioned stimulus and to contextual stimuli. Behav. Neurosci. 111, 683-691.

Murchison, C. F., Zhang, X. Y., Zhang, W. P., Ouyang, M., Lee, A., and Thomas, S. A. (2004). A distinct role for norepinephrine in memory retrieval. Cell 117, 131-143.

Neftel, K. A., Adler, R. H., Kappeli, L., Rossi, M., Dolder, M., Kaser, H. E., Bruggesser, H. H. and Vorkauf, H. (1982). Stage fright in musicians: a model illustrating the effect of beta blockers. Psychosom. Med. 44, 461-469.

Nielson, K.A., Czech, D.A., and Laubmeier, K. K. (1999). Chronic administration of propranolol impairs inhibitory avoidance retention in mice. Neurobiol. Learn Mem. 71, 248-257.

O'Keefe, J., and Nadel, L. (1978). The Hippocampus as a Cognitive Map. Oxford: Clarendon Press.

Oliveira, M. A., and Prado, W. A. (1998). Antinociception induced by stimulating amygdaloid nuclei in rats: changes produced by systemically administered antagonists. Braz. J. Med. Biol. Res. 31, 681-690.

Paxinos, G., and Watson, C. (1998). The Rat Brain in Stereotaxic Coordinates, 4th Edn. New York: Academic Press.

Phillips, R. G., and LeDoux, J. E. (1994). Lesions of the dorsal hippocampal formation interfere with background but not foreground contextual fear conditioning. Learn. Mem. 1, 34-44.

Przybyslawski, J., Roullet, P., and Sara, S. J. (1999). Attenuation of emotional and nonemotional memories after their reactivation: role of betaadrenergic receptors. J. Neurosci. 19, 6623-6628.

Quirk, G. J., Garcia, R., and GonzalezLima, F. (2006). Prefrontal mechanisms in extinction of conditioned fear. Biol. Psychiatry 60, 337-343.

Rodrigues, S. M., Schafe, G. E., and LeDoux, J.E. (2004). Molecular mechanisms underlying emotional learning and memory in the lateral amygdala. Neuron 44, 75-91.

Rodriguez-Romaguera, J., Sotres-Bayon, F., Mueller, D., and Quirk, G. J. (2009). Systemic propranolol acts centrally to reduce conditioned fear in rats without impairing extinction. Biol. Psychiatry $65,887-892$

Roozendaal, B., Castello, N. A., Vedana, G., Barsegyan, A., and McGaugh, J. L. (2008). Noradrenergic activation of the basolateral amygdala modulates consolidation of object recognition memory. Neurobiol. Learn. Mem. 90, 576-579.

Roozendaal, B., Hahn, E. L., Nathan, S. V., de Quervain, D. J., and McGaugh, J. L. (2004). Glucocorticoid effects on memory retrieval require concurrent noradrenergic activity in the hippocampus and basolateral amygdala. $J$. Neurosci. 24, 8161-8169.

Sabetkasai, M., Doost-Mohammady, R., and Zarrindast, M. R. (1997). Opposite influences of different adrenoceptors on baclofen-induced antinociception in mice. Pharmacol. Toxicol. 80, 6-10.

Schafe, G. E., and LeDoux, J. E. (2000) Memory consolidation of auditory pavlovian fear conditioning requires protein synthesis and protein kinase A in the amygdala. J. Neurosci. 20, RC96.

Schafe, G. E., Nadel, N. V., Sullivan, G. M., Harris, A., and LeDoux, J. E. (1999). Memory consolidation for contextual and auditory fear conditioning is dependent on protein synthesis, PKA, and MAP kinase. Learn. Mem. $6,97-110$

Sotres-Bayon, F., Bush, D. E. A., and LeDoux, J. E. (2004). Emotional perseveration: an update on prefrontal-amygdala interactions in fear extinction. Learn. Mem. 11, 525-535.

Sullivan, G. M., Coplan, J. D., Kent, J. M., and Gorman, J. M. (1999). The noradrenergic system in pathological anxiety: a focus on panic with relevance to generalized anxiety and phobias. Biol. Psychiatry 46, 1205-1218.

Tully, K., Li, Y., Tsvetkov, E., and Bolshakov, V. Y. (2007). Norepinephrine enables the induction of associative long-term potentiation at thalamo-amygdala synapses. Proc. Natl. Acad. Sci. U.S.A. 104, 14146-14150.

Wilensky, A. E., Schafe, G. E., and LeDoux, J. E. (1999). Functional inactivation of the amygdala before but not after auditory fear conditioning prevents memory formation. J. Neurosci. 19, RC48.

Wilensky, A. E., Schafe, G. E., and LeDoux, J. E. (2000). The amygdala modulates memory consolidation of fear-motivated inhibitory avoidance learning but not classical fear conditioning. $J$. Neurosci. 20, 7059-7066.

Winder, D. G., Martin, K. C., Muzzio, I. A., Rohrer, D., Chruscinski, A., Kobilka, B., and Kandel, E. R. (1999). ERK plays a regulatory role in induction of LTP by theta frequency stimulation and its modulation by beta-adrenergic receptors. Neuron 24, 715-726.

Conflict of Interest Statement: The authors declare that the research was conducted in the absence of any commercial or financial relationships that could be construed as a potential conflict of interest.

Received: 27 May 2010; paperpending published: 31 May 2010; accepted: 26 July 2010; published online: 26 October 2010.

Citation: Bush DE, Caparosa EM, Gekker $A$ and LeDoux J (2010) Beta-adrenergic receptors in the lateral nucleus of the amygdala contribute to the acquisition but not the consolidation of auditory fear conditioning. Front. Behav. Neurosci. 4:154. doi: 10.3389/fnbeh.2010.00154

Copyright (c) 2010 Bush, Caparosa, Gekker and LeDoux. This is an open-access article subject to an exclusive license agreement between the authors and the Frontiers Research Foundation, which permits unrestricted use, distribution, and reproduction in any medium, provided the original authors and source are credited. 